\title{
Fabrication of $\mathrm{Zn}$-treated $\mathrm{ACF} / \mathrm{TiO}_{2}$ Composites and Their Photocataytic Activity for Degradation of Methylene Blue
}

\author{
Yu-Gyoung Go, Feng-Jun Zhang*, Ming-Liang Chen and Won-Chun $\mathrm{Oh}^{\dagger}$ \\ Department of Advanced Materials \& Science Engineering, Hanseo University, Chungnam 356-706, Korea \\ *Anhui Key Laboratory of Advanced Building Materials, Anhui University of Architecture, \\ Anhui Hefei 230022 P. R. China
}

(Received November 16, 2008 : Received in reviced form January 6, 2009 : Accepted February 17, 2009)

\begin{abstract}
In this paper, non-treated $\mathrm{ACF}$ (Activated Carbon Fiber) $/ \mathrm{TiO}_{2}$ and $\mathrm{Zn}$-treated $\mathrm{ACF} / \mathrm{TiO}{ }_{2}$ were prepared. The prepared composites were characterized in terms of their structural crystallinity, elemental identification and photocatalytic activity. XRD patterns of the composites showed that the non-treated ACF/ $\mathrm{TiO}_{2}$ composite contained only typical single and clear anatase forms while the $\mathrm{Zn}$-treated $\mathrm{ACF} / \mathrm{TiO}_{2}$ contained a mixed anatase and rutile phase with a unique $\mathrm{ZnO}$ peak. SEM results show that the titanium complex particles are uniformly distributed on and around the fiber and that the titanium complex particles are more regularly distributed on and around the ACF surfaces upon an increase of the $\mathrm{ZnCl}_{2}$ concentration. These EDX spectra show the presence of peaks from the $\mathrm{C}, \mathrm{O}$ and Ti elements. Moreover, peaks of the $\mathrm{Zn}$ element were observed in the $\mathrm{Zn}$-treated $\mathrm{ACF} / \mathrm{TiO}_{2}$ composites. The prominent photocatalytic activity of the $\mathrm{Zn}$-treated $\mathrm{ACF} /$ $\mathrm{TiO}_{2}$ can be attributed to the three different effects of photo-degradation: doping, absorptivity by an electron transfer, and adsorptivity of porous ACFs between the $\mathrm{Zn}-\mathrm{TiO}_{2}$ and $\mathrm{Zn}-\mathrm{ACF}$.
\end{abstract}

Key words $\underline{\mathrm{TiO}}_{2}, \mathrm{ZnO}, \mathrm{ACF}$, photocatalytic, methylene blue.

\section{Introduction}

Heterogeneous photocatalysis is a very promising destructive technique to complete mineralization of dye as it has already been applied with success on the degradation of different categories of organic compounds combining the low cost, the mild conditions and the possibility of using sunlight as the source of irradiation. ${ }^{1)}$ $\mathrm{TiO}_{2}$ have been proved to be an important photocatalyst for degradation of environmental contaminants. ${ }^{2,3)}$ However, in field applications, there are at least two obvious problems arising from using $\mathrm{TiO}_{2}$ as a photocatalyst. Lower photonic efficiency and usually be induced only by ultraviolet light limit the application of $\mathrm{TiO}_{2}$. In order to solve these problems, there are two ways at present. One way to improve the photocatalytic activity of $\mathrm{TiO}_{2}$ particles is the manipulation of shape, size and surface properties of $\mathrm{TiO}_{2}$ particles. ${ }^{4)}$ Another way to enhance the photocatalytic activity is the coating and doping of other materials, including metal ions and semiconductors, onto the surface of $\mathrm{TiO}_{2}$ nanoparticles. ${ }^{5-7)}$

Corresponding author

E-Mail :wc_oh@hanseo.ac.kr (W. C. Oh).
$\mathrm{ZnO}$ has been also conceived as a significant candidate that was reportedly known to be more efficient than $\mathrm{TiO}_{2}$ in photoxidation of organic compounds. The band gap energies of $\mathrm{ZnO}$ and $\mathrm{TiO}_{2}$ are similar to each other (approximately $3.2 \mathrm{eV}$ ).

In the past decade, there were a number of studies related to the photocatalytic activity of $\mathrm{TiO}_{2}$ and $\mathrm{ZnO}^{8-14)}$ They are known as low operation temperature, low cost, low energy consumption, and nontoxic and very effective semiconductor photocatalysts. The photocatalytic properties of $\mathrm{TiO}_{2} / \mathrm{ZnO}$ composite photocatalysts remain largely unexplored although a few studies focused on $\mathrm{TiO}_{2} / \mathrm{ZnO}$ composites. In the present work, heterojunction films composed of $\mathrm{ZnO}$ and $\mathrm{TiO}_{2}$ layers were provided to improve photoelectrocatalytic properties. ${ }^{9,10} \mathrm{Li}$ and his coworkers $^{11)}$ have investigated the differences in the interaction of $\mathrm{MnO}_{2}$ with $\mathrm{ZnO}$ and $\mathrm{TiO}_{2}$ in suspension and their photocatalytic degradation. Evgenidou et $a l^{12)}$ has reported the photocatalytic oxidation of methyl parathion over $\mathrm{TiO}_{2}$ and $\mathrm{ZnO}$ suspensions. Uddin et al have studied the influence of $\mathrm{TiO}_{2}$ and $\mathrm{ZnO}$ photocatalysts on adsorption and degradation behaviour of Erythrosine. ${ }^{13)}$ The photocatalytic activity for degradation of methyl orange using the nanosized $\mathrm{TiO}_{2} / \mathrm{ZnO}$ 
composite catalyst has been reported by Liao et al. ${ }^{14)}$

In previous works, ${ }^{15,16)}$ it was found that $\mathrm{TiO}_{2} / \mathrm{ACF}$ composite has excellent photocatalytic activity in the degradation of methyl blue (MB), which is a representative azo dye. However, the influences of $\mathrm{ZnO}$ on photocatalyst $\mathrm{TiO}_{2} / \mathrm{ACF}$ in the degradation of $\mathrm{MB}$, and the effect of $\mathrm{ZnO}$ on the photocatalytic activity of $\mathrm{TiO}_{2} / \mathrm{ACF}$, are not known well. Hence, the objective of this research is to (1) study the influence of $\mathrm{ZnO}$ on $\mathrm{TiO}_{2} / \mathrm{ACF}$ photocatalytic degradation of MB, (2) examine the effect of $\mathrm{ZnO}$ on $\mathrm{TiO}_{2} / \mathrm{ACF}$ photocatalytic degradation of MB.

In this study, the photocatalytic degradation of $\mathrm{MB}$ has been investigated using non-treated $\mathrm{ACF} / \mathrm{TiO}_{2}$ and $\mathrm{Zn}$ treated $\mathrm{ACF} / \mathrm{TiO}_{2}$ as catalysts. Titanium iso propoxide (TIP) rather than the commonly employed $\mathrm{TiO}_{2}$ powder was chosen as the precursor to increase the mixing rate of $\mathrm{TiO}_{2}$ and ACF. The prepared composites were characterized by X-ray diffraction (XRD), scanning electron microscope (SEM), energy dispersive X-ray (EDX). The catalytic efficiency of the prepared composites was evaluated by the photodegradation of MB.

\section{Experimental Procedure}

\subsection{Materials}

Activated Carbon Fiber (ACF) was purchased from EAST ASIS Carbon Fibers Co., Ltd, Anshan, China. Table 1 shows the properties of ACF. Titanium iso propoxide (TIP, 97\%) as a titanium source for the preparation of $\mathrm{TiO}_{2} / \mathrm{ACF}$ composites were purchased from Kanto Chemical Company (Tokyo, Japan). Zinc chloride (extra pure reagent, $\mathrm{ZnCl}_{2}$ ) as the zinc source for $\mathrm{ZnO}$ was purchased from Daejung Chemical \& Metal Co., Ltd, Korea. The MB was used as analytical grade which was purchased from Duksan Pure Chemical Co., Ltd, Korea. It was selected because it can be readily under anaerobic conditions to produce potentially more hazardous aromatic amines.

\subsection{Preparation of samples}

In this experimental, at first, $10 \mathrm{~g}$ ACF power was added into $50 \mathrm{~mL} 0.1 \mathrm{M} \mathrm{HCl}$ solution and stirred 2 hours and dry at $378 \mathrm{~K}$. Then the pretreated ACF was put into the different concentration of $\mathrm{ZnCl}_{2}$ solution and stirred 30 minutes, after heat treated at $773 \mathrm{~K}$, we obtained the $\mathrm{Zn}-\mathrm{ACF}$ materials. The $\mathrm{Zn}-\mathrm{ACF}$ was put into the mixing solution of TIP and benzene. Then the solutions were homogenized under reflux at $343 \mathrm{~K}$ for 5 hours using a magnetic stirrer in a vial, and then the stirring solutions were transformed to one kind of gels, and these gels were heat treated at $973 \mathrm{~K}$ for 1 hour. And then the $\mathrm{Zn}$ treated $\mathrm{ACF} / \mathrm{TiO}_{2}$ composites were prepared. In this state, zinc ions can be formed as salts combined with functional groups on the ACF surfaces. The nomenclatures of prepared samples are listed in Table 2.

\subsection{Characteristics and investigations of the samples}

XRD was used for crystal phase identification and estimation of the anastase-to-rutile ratio. XRD patterns were obtained at room temperature with a diffractometer Shimata XD-D1 (Japan) using $\mathrm{Cu} \mathrm{K} \alpha$ radiation. SEM was used to observe the surface state and porous structure of the non-treated $\mathrm{ACF} / \mathrm{TiO}_{2}$ and $\mathrm{Zn}$-treated $\mathrm{ACF} / \mathrm{TiO}_{2}$ composites using a JSM-5200 JOEL electron microscope (Japan). EDX was used to measure the elemental analysis of the non-treated $\mathrm{ACF} / \mathrm{TiO}_{2}$ and $\mathrm{Zn}$ treated $\mathrm{ACF} / \mathrm{TiO}_{2}$ composites. UV-VIS spectra for the $\mathrm{MB}$ solution degraded by non-treated $\mathrm{ACF} / \mathrm{TiO}_{2}$ and $\mathrm{Zn}$ -

Table 1. The properties of activated carbon fiber (ACF).

\begin{tabular}{cc}
\hline Physical properties & Units \\
\hline Density & $1.23 \sim 1.91 \mathrm{~g} / \mathrm{mL}$ \\
Electrical Resistivity & $5.2 \times 10^{-3} \sim 6.8 \times 10^{-3} \Omega \cdot \mathrm{cm}$ \\
Diameter & $12 \sim 15 \mu$ \\
Tensile Strength & $4 \sim 6 \times 10^{8} \mathrm{~Pa}$ \\
Tensile Modulus & $3 \times 10^{10} \sim 4 \times 10^{10} \mathrm{~Pa}$ \\
Elemental carbon & $\geq 95 \mathrm{wt} \%$ \\
\hline
\end{tabular}

Table 2. Nomenclatures of non-treated $\mathrm{ACF} / \mathrm{TiO}_{2}$ and $\mathrm{Zn}$-treated $\mathrm{ACF} / \mathrm{TiO}{ }_{2}$ composites.

\begin{tabular}{cc}
\hline Preparation method & Nomenclatures \\
\hline $\mathrm{ACF}+$ Titanium iso propoxide & AT \\
$0.1 \mathrm{M} \mathrm{HCl}+\mathrm{ACF}+$ Titanium iso propoxide & AT1 \\
$0.05 \mathrm{M} \mathrm{ZnCl}{ }_{2}+0.1 \mathrm{M} \mathrm{HCl}+\mathrm{ACF}+$ Titanium iso propoxide & ZAT2 \\
$0.1 \mathrm{M} \mathrm{ZnCl}+0.1 \mathrm{M} \mathrm{HCl}+\mathrm{ACF}+$ Titanium iso propoxide & ZAT3 \\
$0.5 \mathrm{M} \mathrm{ZnCl}_{2}+0.1 \mathrm{M} \mathrm{HCl}+\mathrm{ACF}+$ Titanium iso propoxide & \\
\hline
\end{tabular}


treated $\mathrm{ACF} / \mathrm{TiO}_{2}$ composites dispersion under different conditions was recorded using a Genspec III (Hitachi, Japan) spectrometer.

\subsection{Photocatalytic decomposition}

The photocatalytic decomposition was performed by using non-treated $\mathrm{ACF} / \mathrm{TiO}_{2}$ and $\mathrm{Zn}$-treated $\mathrm{ACF} / \mathrm{TiO}_{2}$ composites in a $100 \mathrm{~mL}$ glass container and then irradiating the system with $20 \mathrm{~W}$ UV light at $365 \mathrm{~nm}$. The initial MB concentration was chosen $1.0 \times 10^{-5} \mathrm{~mol} / \mathrm{L}$. The amount of suspended composites was kept at $1 \mathrm{~g} / \mathrm{L}$ in $50 \mathrm{~mL} \mathrm{MB}$ solution. Before turning on UV lamp, the solution mixed with composites was kept in the dark for at least 2 hours, allowing the adsorption-desorption equilibrium to be reached. Then, the solution was irradiated with UV. The first sample was taken out at the end of the dark adsorption period (just before the light was turned on), in order to determine the $\mathrm{MB}$ concentration in solution, which was hereafter considered as the initial concentration $\left(\mathrm{c}_{0}\right)$ after dark adsorption. Samples were then withdrawn regularly from the reactor by an order of $30 \mathrm{~min}, 90 \mathrm{~min}, 150 \mathrm{~min}, 300 \mathrm{~min}$, and immediately centrifuged to separate any suspended solid. The clean transparent solution was analyzed by using a UV-vis spectrophotometer. The blue color of the solution faded gradually with time due to the adsorption and decomposition of MB. And then the concentration of MB in the solution was determined as a function of irradiation time from the absorbance change at a wavelength of $660 \mathrm{~nm}$.

\section{Results and Discussion}

\subsection{Structure and morphology of non-treated $\mathrm{ACF} / \mathrm{TiO}_{2}$ and $\mathrm{Zn}$-treated $\mathrm{ACF} / \mathrm{TiO}_{2}$}

The XRD analysis results for the catalyst are shown in Fig. 1 Diffraction peaks corresponding to anatase and rutile phases have been marked with ' $A$ ' and ' $R$ ', respectively; diffraction peaks corresponding to $\mathrm{ZnO}$ phase has been marked with ' $Z$ '. XRD patterns of the composites showed that the non-treated $\mathrm{ACF} / \mathrm{TiO}_{2}$ composite contained only a typical single and clear anatase forms while the $\mathrm{Zn}$-treated $\mathrm{ACF} / \mathrm{TiO}_{2}$ contained a mixing anatase and rutile phase. For the non-treated $\mathrm{ACF} / \mathrm{TiO}_{2}$ composite, after the heat treatment at $973 \mathrm{~K}$ for 1hour, the main crystalline phase is not transformed to the rutile structure. The major peaks at 25.3, 37.8, 48.0,

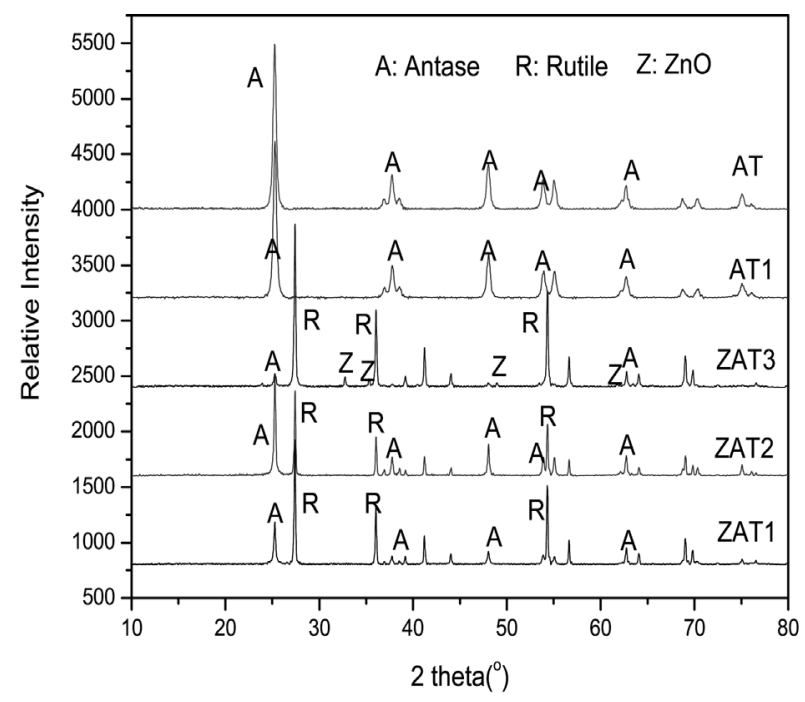

Fig. 1. XRD patterns of non-treated $\mathrm{ACF} / \mathrm{TiO}_{2}$ and $\mathrm{Zn}$-treated $\mathrm{ACF} / \mathrm{TiO}_{2}$ composites.

53.8, 54.9 and 62.5 are the diffractions of (101), (004), (200), (105), (211) and (204) planes of anatase, indicating the prepared non-treated $\mathrm{ACF} / \mathrm{TiO}_{2}$ composites existed in anatase state. According to the former study, ${ }^{17-20)}$ it is well known that the crystal structure of the titanium dioxide is mainly determined by the heat treatment temperature. The result is in accordance with references. ${ }^{15,16)}$

However, for the $\mathrm{Zn}$-treated $\mathrm{ACF} / \mathrm{TiO}_{2}$ composites, the peaks at 25.3, 37.8, 48.0 and 62.5 are the diffractions of (101), (004), (200) and (204) planes of anatase, indicating the developed $\mathrm{CNT} / \mathrm{TiO}_{2}$ composites existed in anatase state. The peaks at 27.4, 36.1, 41.2 and 54.3 belong to the diffraction peaks of (110), (101), (111) and (211) of rutile. Therefore, it can be concluded that the developed $\mathrm{Zn}$-treated $\mathrm{ACF} / \mathrm{TiO}_{2}$ composites had a mixing structures of anatase and rutile crystals. As we known, the anatase phase formed below $773 \mathrm{~K}$ starts to transform to rutiletype structure above $873 \mathrm{~K}$ and changed into single phase of rutile at $973 \sim 1173 \mathrm{~K}^{21)}$ It is evident, from these studies, that zinc treatment induces the phase transformation from anatase to rutile. The inducement in the phase transition with $\mathrm{Zn}^{2+}$ doping is attributed to the oxygen vacancies in the structure caused by doping; essential for charge compensation of lower valent cations. These vacancies enhance the transport of atoms required for phase transition from anatase to rutile. ${ }^{22)}$ This is exactly the reverse phenomenon reported in the doping of higher valent cations, where phase transition has been 
expected to be retarded by forming interstitial $\mathrm{Ti}^{3+}$ cations that suppresses atomic transport in the anatase phase. $^{23)}$ Therefore, the effect of $\mathrm{Zn}^{2+}$ doping is to introduce oxygen vacancies in the $\mathrm{TiO}_{2}$ structure which enhances the diffusion of atoms in the system. This mechanism is supposed to be responsible for the phase transition of $\mathrm{Zn}$-treated $\mathrm{ACF} / \mathrm{TiO}_{2}$ as compared to nontreated $\mathrm{ACF} / \mathrm{TiO}_{2}$.

Moreover, in the curve of ZAT3, we can clearly find the peaks of $\mathrm{ZnO}$, but for ZAT1 and ZAT2, we could not observe characteristic peaks of $\mathrm{ZnO}$ in the XRD patterns. This implies either zinc was incorporated in the crystallites of $\mathrm{TiO}_{2}$ or $\mathrm{ZnO}$ was very small and highly dispersed, which was further supported by observation via SEM and EDX elemental microanalysis of Zn-treated $\mathrm{ACF} / \mathrm{TiO}_{2}$. The similar phenomena can be observed in the references. ${ }^{24)}$ The photodecomposition for dye in liquid reaction was enhanced over $\mathrm{Zn}$-incorporated $\mathrm{TiO}_{2}$ compared with pure $\mathrm{TiO}_{2}{ }^{25}$ )

Fig. 2 shows the SEM surface morphology of nontreated $\mathrm{ACF} / \mathrm{TiO}_{2}$ and $\mathrm{Zn}$-treated $\mathrm{ACF} / \mathrm{TiO}_{2}$ composites. It shows that $\mathrm{TiO}_{2}$ particles uniformly covered the surface of ACF, which was beneficial for the photocatalytic reaction because the photocatalytic reaction is carried out on the external surfaces of the $\mathrm{TiO}_{2} / \mathrm{ACF}$ composites catalysts by existing reactants using UV light and the nono-size structured catalyst could provide a more effective surface for MB adsorption and UV light absorption. ${ }^{15)}$ Moreover, for $\mathrm{Zn}$-treated $\mathrm{ACF} / \mathrm{TiO}_{2}$ composites, the titanium complexe particles more regularly distributed on and around the ACF surfaces with the increase of $\mathrm{ZnCl}_{2}$ concentration. It was considered that a good dispersion of small particles could provide more reactive sites for the reactants than aggregated particles. Accordingly, a Heterogeneous $\mathrm{TiO}_{2}$ particle distribution was expected for a high photocatalytic yield. ${ }^{1)}$ Therefore, the higher photocatalytic activity of the $\mathrm{Zn}$-treated $\mathrm{ACF} / \mathrm{TiO}_{2}$ composite prepared might be attributed to chemical degradation by the homogenous distribution of titanium complexes including $\mathrm{TiO}_{2}, \mathrm{ZnO}$ and physical adsorption by the activated carbon fiber.

Fig. 3 shows the results of elemental analysis by EDX spectra of non-treated $\mathrm{ACF} / \mathrm{TiO}_{2}$ and $\mathrm{Zn}$-treated $\mathrm{ACF} /$ $\mathrm{TiO}_{2}$ composites. These spectra show the presence of peaks from the $\mathrm{C}, \mathrm{O}$ and $\mathrm{Ti}$ elements. For the $\mathrm{Zn}$-treated $\mathrm{ACF} / \mathrm{TiO}_{2}$ composites, we observed the peaks of the $\mathrm{Zn}$ element. It was observed that for most of these spectra from these samples stronger peaks from carbon and $\mathrm{Ti}$ metal are seen than for any other elements. The results of elemental composition analysis of the composite series are listed in Table 3 From the table, it is shown that carbon and $\mathrm{Ti}$ are present as major elements in the composite series. As expected, it was observed that the $\mathrm{Zn}$ contents of $\mathrm{Zn}$-treated $\mathrm{ACF} / \mathrm{TiO}_{2}$ composites show an increase with an increase of $\mathrm{ZnCl}_{2}$ concentration.

\subsection{Photocatalytic activity}

The UV/VIS absorbance spectra of MB concentration at $1.0 \times 10^{5} \mathrm{~mol} / \mathrm{L}$ against the non-treated $\mathrm{ACF} / \mathrm{TiO}_{2}$ and $\mathrm{Zn}$-treated $\mathrm{ACF} / \mathrm{TiO}_{2}$ composite series are shown in Fig. 4 In Fig. 4 the absorbance values decreased with an increase in UV irradiation time. All the samples showed marked and fast adsorption of MB. The effect of the high crystallinity of anatase phase on photocatalytic degradation of MB has been shown. ${ }^{13)}$ However, it is shown that the absorbance of AT and AT1 is lower than that of ZAT1, ZAT2 and ZAT3. It was considered that potential transformation of the structural phase to rutile was shown to reduce the photocatalytic activity of carbon/ $/ \mathrm{TiO}_{2}$ catalysis, similar results have also been observed by Chen et al. ${ }^{17)}$ Fig. 5 shows changes in relative concentration $\left(\mathrm{c} / \mathrm{c}_{0}\right)$ of $\mathrm{MB}$ under UV light irradiation in the solution. MB removal with non-treated $\mathrm{ACF} / \mathrm{TiO}_{2}$ and Zn-treated $\mathrm{ACF} / \mathrm{TiO}_{2}$ composite photocatalysts is carried out to observe the UV photolysis effect for the MB solution. From the result between $\mathrm{c} / \mathrm{c}_{0}$ and time, it was observed that the relative concentration

Table 3. EDX elemental microanalysis of non-treated $\mathrm{ACF} / \mathrm{TiO}_{2}$ and $\mathrm{Zn}$-treated $\mathrm{ACF} / \mathrm{TiO}_{2}$ composites.

\begin{tabular}{ccccc}
\hline Sample & C & O & Ti & Zn \\
\hline AT & 40.70 & 27.42 & 31.56 & 0 \\
AT1 & 53.84 & 21.79 & 23.90 & 0 \\
ZAT1 & 48.67 & 21.12 & 28.03 & 1.17 \\
ZAT2 & 48.25 & 22.28 & 27.08 & 1.47 \\
ZAT3 & 47.74 & 21.51 & 27.54 & 2.13 \\
\hline
\end{tabular}




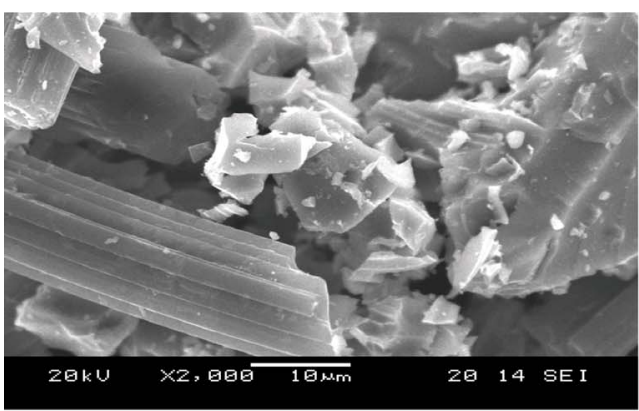

(a)

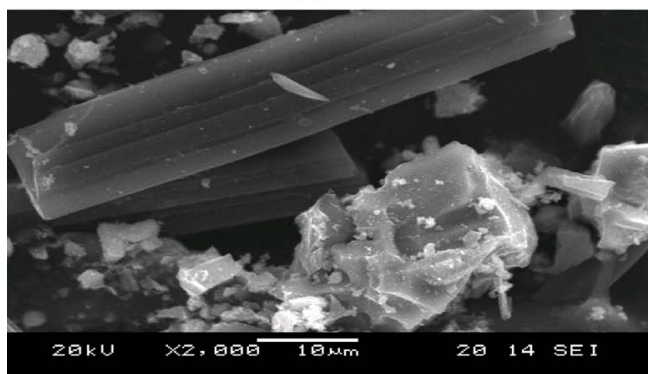

(c)

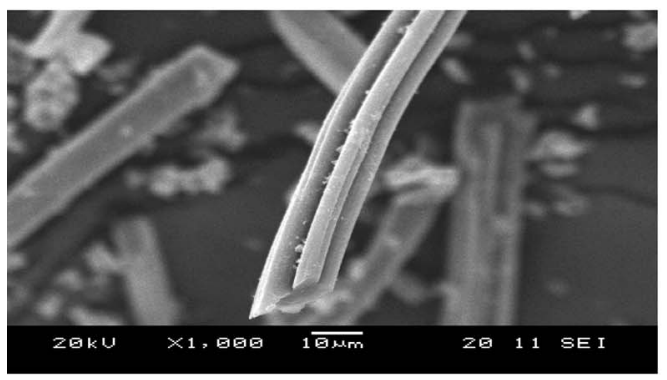

(e)

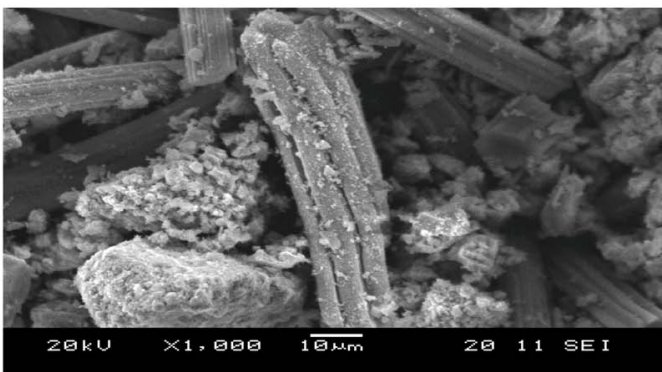

(g)

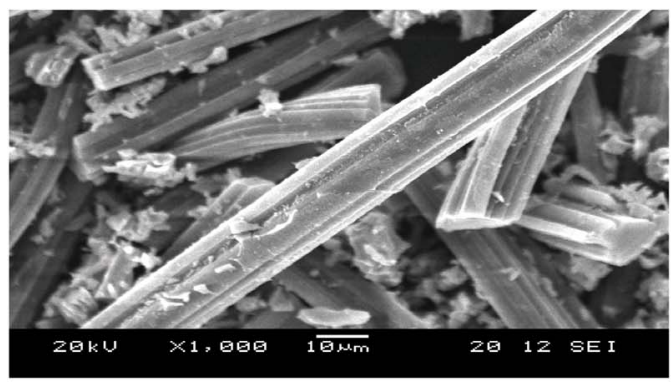

(i)

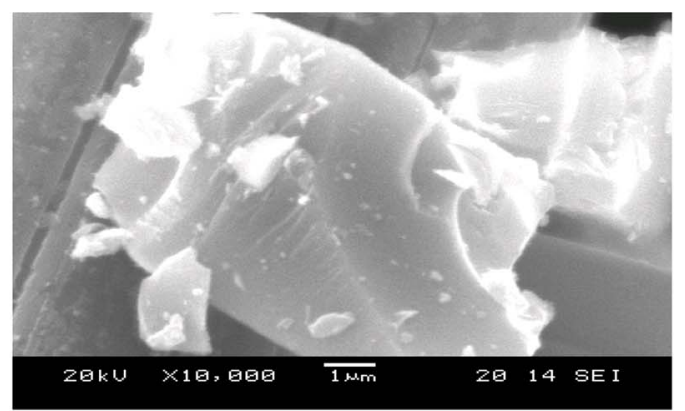

(b)

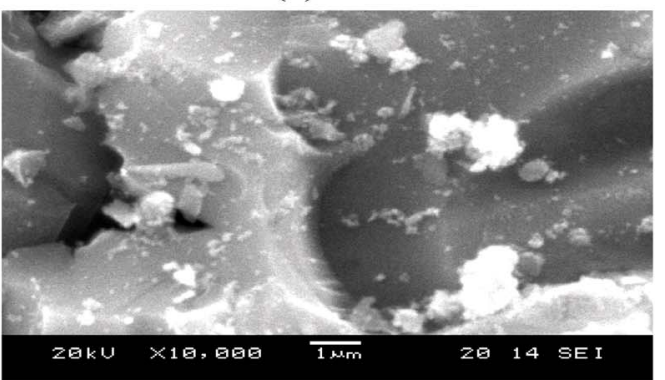

(d)

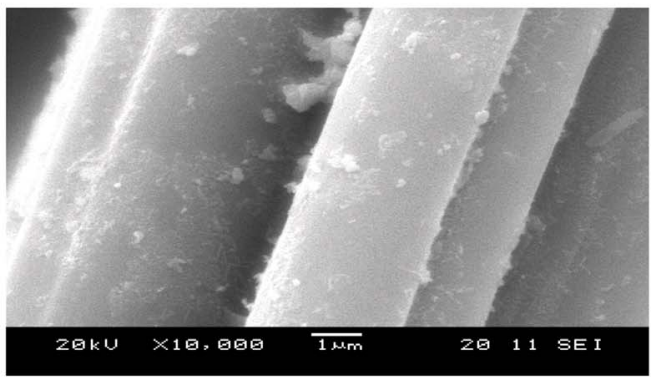

(f)

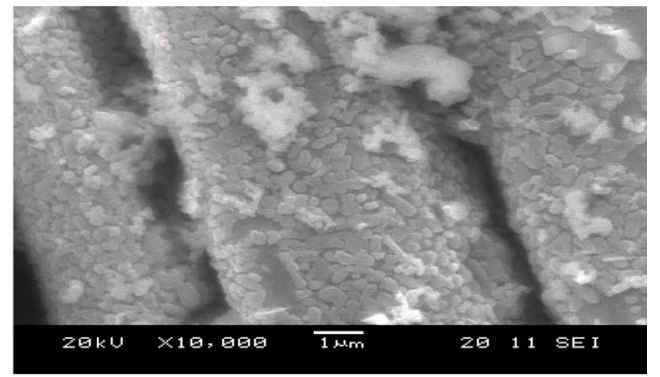

(h)

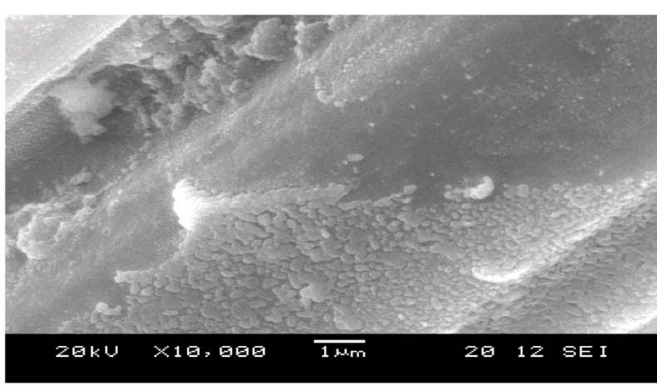

(j)

Fig. 2. SEM images of non-treated $\mathrm{ACF} / \mathrm{TiO}_{2}$ and $\mathrm{Zn}$-treated $\mathrm{ACF} / \mathrm{TiO}{ }_{2}$ composites: (a) $\mathrm{AT}$ (over-all scale), (b) $\mathrm{AT}$ (close-up), (c) AT1 (over-all scale), (d) AT1 (close-up), (e) ZAT1(over-all scale), (f) ZAT1 (close-up), (g) ZAT2 (over-all scale), (h) ZAT2 (closeup), (i) ZAT3 (over-all scale), (j) ZAT3 (close-up) 


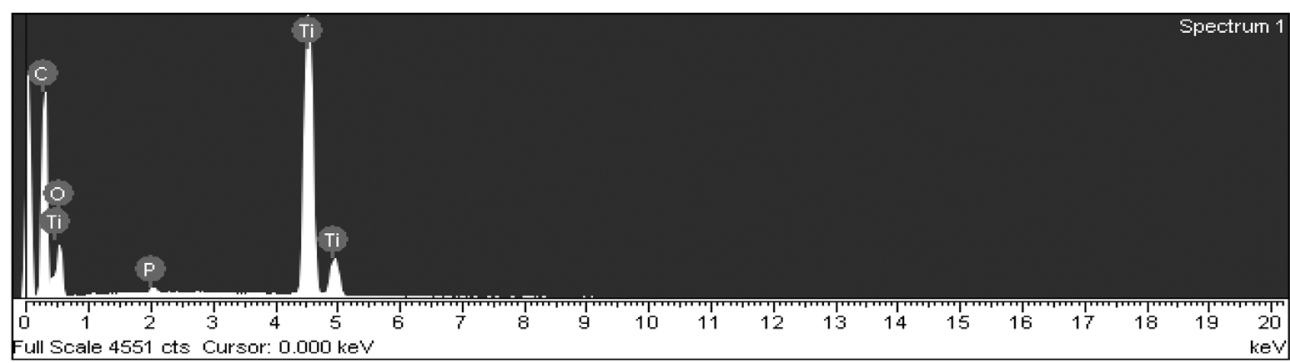

(a)

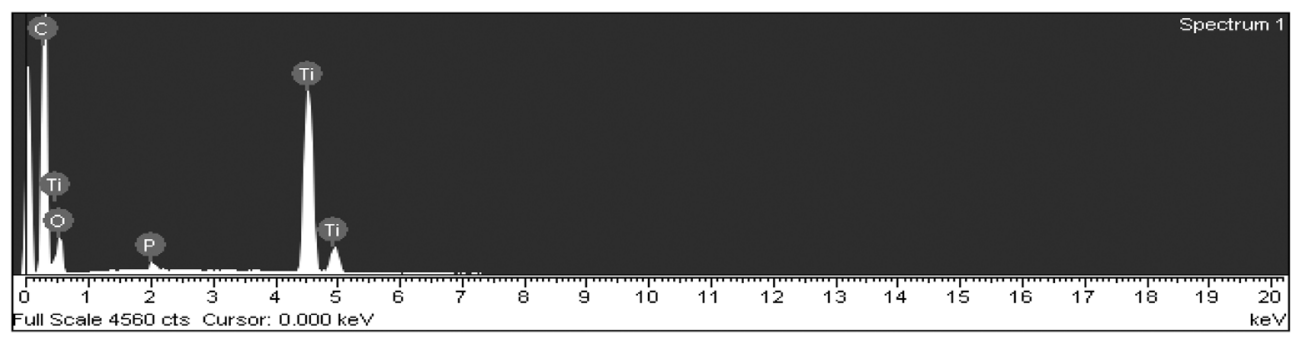

(b)

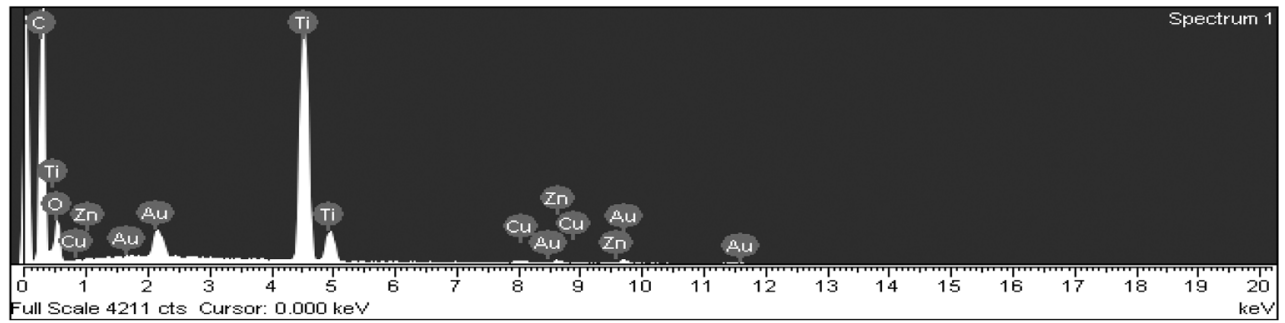

(c)

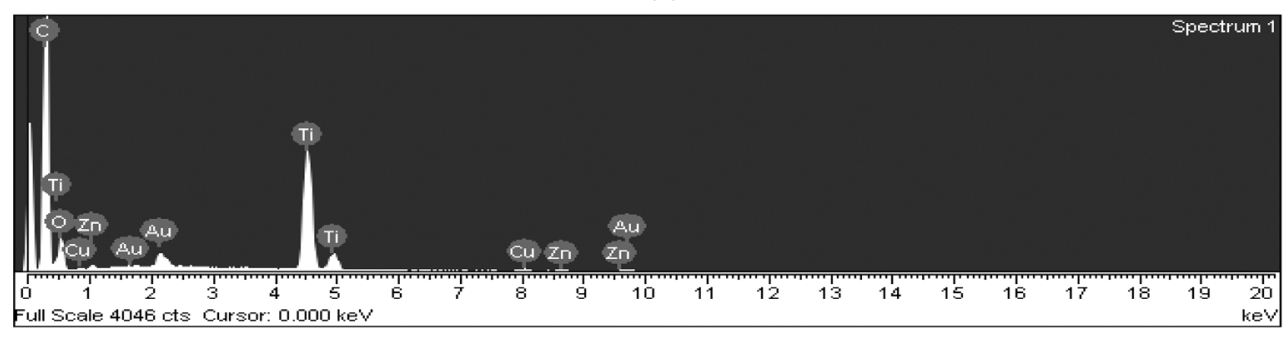

(d)

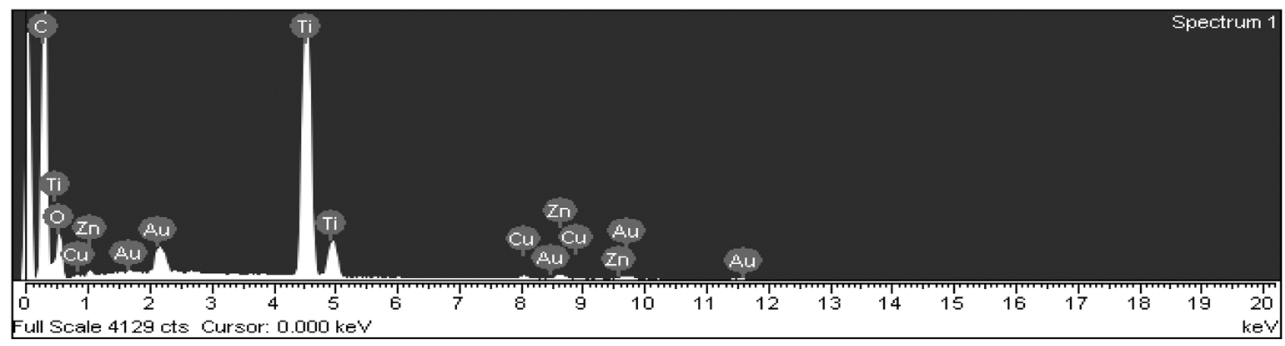

(e)

Fig. 3. EDX elemental microanalysis of non-treated $\mathrm{ACF} / \mathrm{TiO} 2$ and $\mathrm{Zn}$-treated $\mathrm{ACF} / \mathrm{TiO}_{2}$ composites: (a) AT, (b) AT1,(c) ZAT1, (d) $\mathrm{ZAT}_{2}$ and (e) ZAT3.

of MB for ZAT1, ZAT2 and ZAT3 is lower than that of AT and AT1 before turning on UV lamp, probably because the removal of $\mathrm{MB}$ is the main adsorption of $\mathrm{ACF}$, for $\mathrm{Zn}$-treated $\mathrm{ACF} / \mathrm{TiO}_{2}$ composites, the titanium complexe particles more regularly distributed on and around the ACF surfaces with the increase of $\mathrm{ZnCl}_{2}$ concentration, which decrease the surface area of the composites. Moreover, the relative concentrations of $\mathrm{MB}$ 

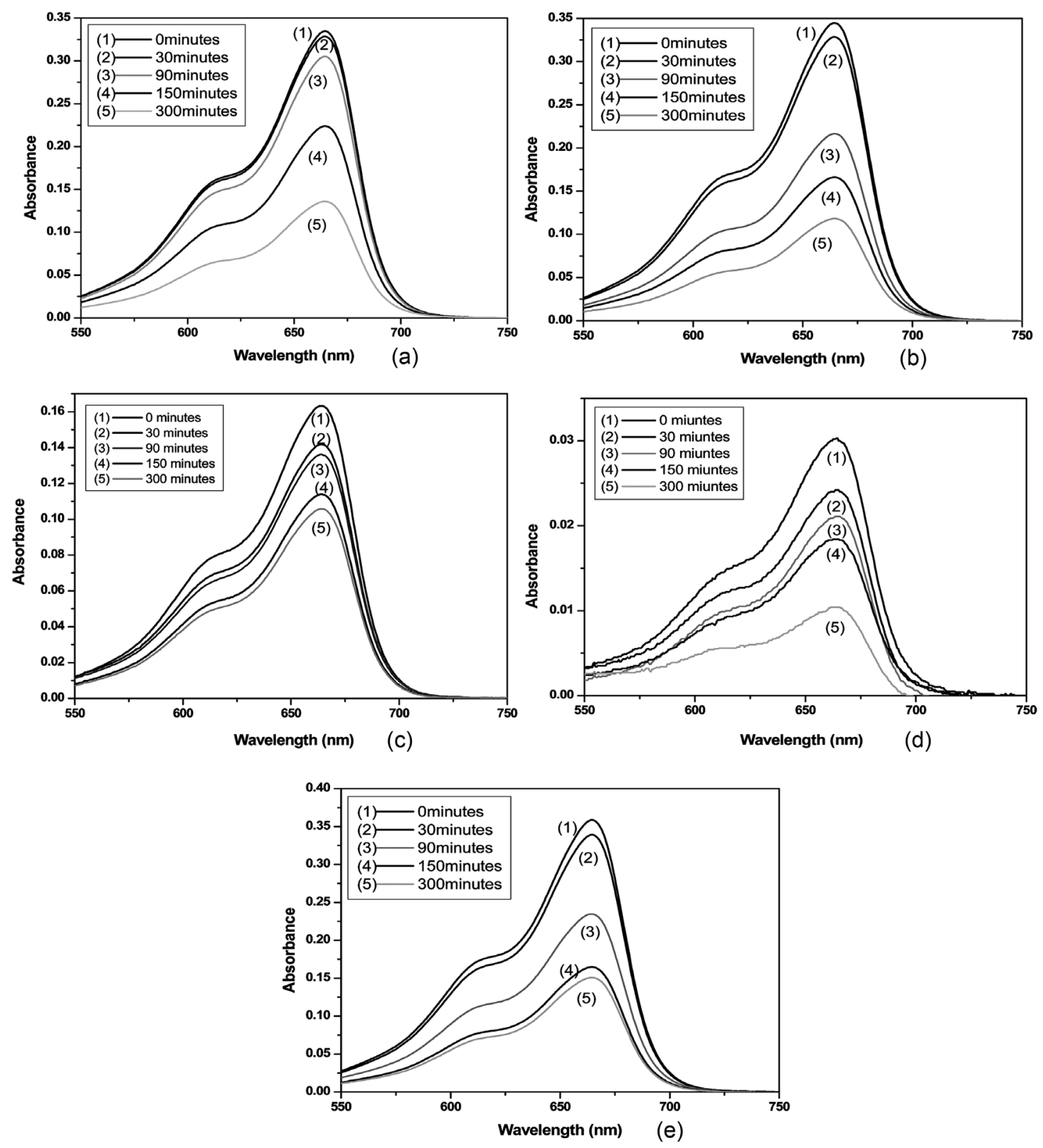

Fig. 4. UV/Vis spectra of $\mathrm{MB}$ concentration against non-treated $\mathrm{ACF} / \mathrm{TiO}_{2}$ and $\mathrm{Zn}$-treated $\mathrm{ACF} / \mathrm{TiO}_{2}$ composites as time function: (a) AT, (b) AT1, (c) ZAT1, (d) ZAT2 and (e) ZAT3.

for AT is lower than that of AT1, the acidic and basic active sites on the carbon surfaces can be determined by means of indirect determination, such as measurements of the catalytic activity for the degradation of $\mathrm{MB}{ }^{16)}$ It indicates that the $\mathrm{HCl}$ pretreated composites are in favor of adsorption of MB. However, adsorption-desorption equilibrium to be reached, under UV light, the decaying speeds of relative concentration for ZAT1, ZAT2 and ZAT3 series are steeper than that of AT and AT1. It is considered that photodegradation of $\mathrm{Zn}$-treated $\mathrm{ACF} / \mathrm{TiO}_{2}$ is the main form of the removal of MB. Moreover, the photodegradation of $\mathrm{Zn}$-treated $\mathrm{ACF} / \mathrm{TiO}_{2}$ is higher with the increase of $\mathrm{ZnCl}_{2}$ concentration.

According to the intrinsic semiconducting characteristics of $\mathrm{TiO}_{2}$ and $\mathrm{ZnO}, \mathrm{TiO}_{2}$ is an indirect band gap semiconductor but $\mathrm{ZnO}$ is a direct band gap semiconductor. ${ }^{9-10,26)}$ Theoretically, when p-type semiconductor $\mathrm{ZnO}$ and n-type semiconductor $\mathrm{TiO}_{2}$ form $\mathrm{p}$-n junction, the inner electric field will be formed in the interface. ${ }^{27)}$ At the equilibrium, the inner electric field 


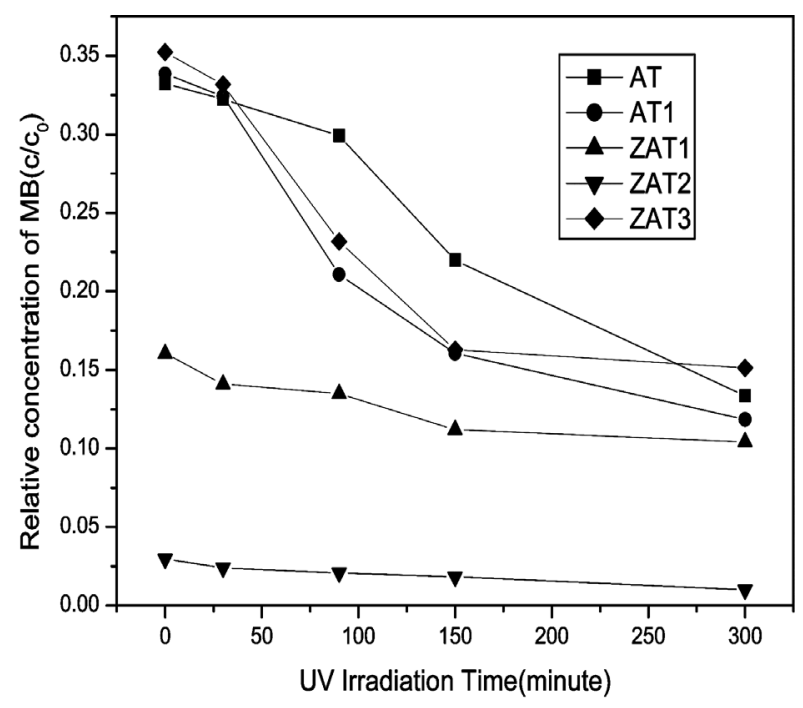

Fig. 5. Dependence of relative concentration $\left(\mathrm{c} / \mathrm{c}_{0}\right)$ of $\mathrm{MB}$ in the aqueous solution on time of UV irradiation for the nontreated $\mathrm{ACF} / \mathrm{TiO}_{2}$ and $\mathrm{Zn}$-treated $\mathrm{ACF} / \mathrm{TiO}_{2}$ composites.

makes p-type semiconductor $\mathrm{ZnO}$ region have the negative charge, while $\mathrm{TiO}_{2}$ region have the positive charge. Under near UV illumination, electron-hole pairs may be created, and the photogenerated electron-hole pairs are separated by the inner electric field. The holes flow into the negative field while the electrons move to the positive field. As a result, the photogenerated electrons and holes are separated efficiently, and the photocatalytic activity is enhanced.

From other side of view, continued adsorption of MB by modified carbon surfaces has provided the substrate for the photocatalysis of $\mathrm{TiO}_{2}$ and $\mathrm{ZnO}{ }^{28)}$ Obviously, photodecomposition of adsorbed $\mathrm{MB}$ enhances the adsorption rate of MB by keeping the adsorptive capacity of the support unsaturated. These two mutually enhanced processes shown in Fig. 6 adsorption of the ACF and photocatalysis of the deposited $\mathrm{TiO}_{2}$ and $\mathrm{ZnO}$, have been combined as the novel properties of the $\mathrm{Zn}$-treated ACF/ $\mathrm{TiO}_{2}$ photocatalyst. Based on these relationships, we therefore can conclude that the degree of removal of MB in the solution should be attributed to the three kinds of effects of photo-degradation by doping, absorptivity by electron transfer and adsoptivity of porous ACFs between the $\mathrm{Zn}-\mathrm{TiO}_{2}$ and the $\mathrm{Zn}-\mathrm{ACF}$.

\section{Conclusions}

In this study, we have prepared non-treated $\mathrm{ACF} / \mathrm{TiO}_{2}$

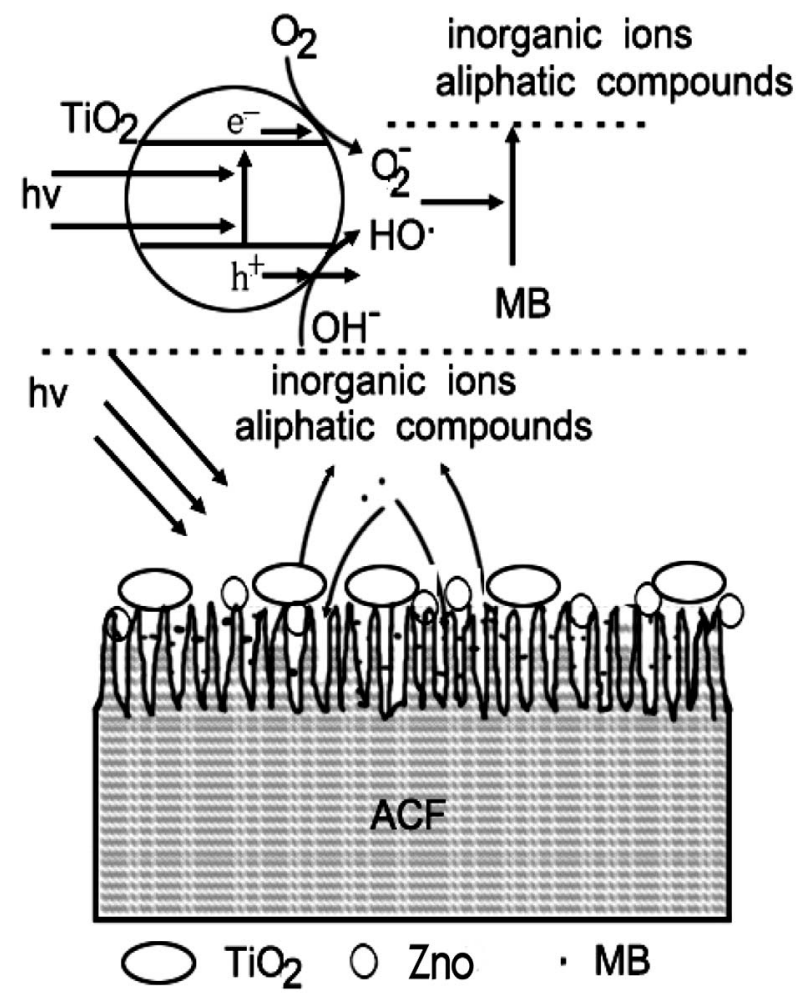

Fig. 6. Schematic diagram for the adsorption and photocatalytic degradation of $\mathrm{MB}$ on the $\mathrm{Zn}$-treated $\mathrm{ACF} / \mathrm{TiO}_{2}$ composites.

and $\mathrm{Zn}$-treated $\mathrm{ACF} / \mathrm{TiO}_{2}$ composite catalysts. The prepared composite materials were characterized by structural crystallinity between $\mathrm{ACF}$ and $\mathrm{TiO}_{2}$, elemental identification and photocatalytic activity. XRD patterns of the composites showed that the non-treated $\mathrm{ACF} / \mathrm{TiO}_{2}$ composite contained only a typical single and clear anatase forms while the $\mathrm{Zn}$-treated $\mathrm{ACF} / \mathrm{TiO}_{2}$ contained a mixing anatase and rutile phase. Form the SEM results, the titanium complex particles are uniformly distributed on and around the fiber, and the titanium complexe particles more regularly distributed on and around the ACF surfaces with the increase of $\mathrm{ZnCl}_{2}$ concentration. These EDX spectra show the presence of peaks from the $\mathrm{C}, \mathrm{O}$ and $\mathrm{Ti}$ elements, for the $\mathrm{Zn}$-treated $\mathrm{ACF} / \mathrm{TiO}_{2}$ composites, and we observed the peaks of the $\mathrm{Zn}$ element. Finally, the prominent photocatalytic activity of the $\mathrm{Zn}$-treated $\mathrm{ACF} / \mathrm{TiO}_{2}$ composites between $\mathrm{c} / \mathrm{c}_{\mathrm{o}}$ and time could be attributed to the three kinds of effects of photo-degradation by doping, absorptivity by electron transfer and adsoptivity of porous ACFs between the $\mathrm{Zn}$ $\mathrm{TiO}_{2}$ and the $\mathrm{Zn}-\mathrm{ACF}$, and the photodegradation of $\mathrm{Zn}$ treated $\mathrm{ACF} / \mathrm{TiO}_{2}$ depends on the $\mathrm{ZnCl}_{2}$ concentration. 


\section{Reference}

1. I. Konstantinou and T. Albanis, Appl. Catal. B. Environ., 42, 319 (2003).

2. N. M. Dimitrijevic, Z. V. Saponjic, B. M. Rabatic and T. Rajh, J. Am. Chem. Soc., 127, 1344 (2005).

3. B. M. Rabatic, N. M. Dimitrijevic and R.E. Cook, Adv. Mater., 18, 1033 (2006).

4. X. Peng, L. Manna, W. Yang and A. P. Alivisatos, Nature., 404, 59 (2000).

5. H. M. Yates, M. G. Nolan, D. W. Sheel and M.E. Pemble, J. Photochem. Photobiol. A: Chem., 179, 213 (2006).

6. Y. Bessekhouad, D. Robert, J.-V. Weber and N. Chaoui, J. Photochem. Photobiol. A: Chem., 167, 49 (2004).

7. D. W. Kim, S. W.Lee, H. S. Jung, J. Y.Kim, H. Shin and K. S. Hong, Int. J. Hydrogen Energy., 32, 3137 (2007).

8. C. S. Zalazar, C. A. Martin and A.E. Cassano, Chem. Eng. Sci., 60, 4311(2005).

9. G. Marci, V. Augugliaro, M. J. Lopez-Munoz, C. Martin, L. Palmisano and V. Rives, J. Phys. Chem. B., 105, 1033(2001).

10. C. C.Hsu and N. L. Wu, J. Photochem. Photobiol. A: Chem., 172, 269(2005).

11. S. Li, Z. Ma, J. Zhang, Y. Wu and Y. Gong, Catal.Today., 8, 12(2008).

12. E. Evgenidou, I. Konstantinou, K. Fytianos, I. Poulios, T. Albanis, Catal. Today., 124, 156 (2007).

13. M. M. Uddin, M. A. Hasnat, A. J. F. Samed and R. K. Majumdar, Dye. Pigm., 75, 207 (2007) .

14. D. L. Liao, C. A. Badour and B. Q. Liao, J. Photochem. Photobiol. A: Chem., 194, 11 (2008).
15. M. L. Chen, C. S Lim and W. C. Oh, Carbon letters., 8(3), 177(2007)

16. W. C. Oh and M. L. Chen, J. Ceram. Process. Res., 9(2), 100( 2008$)$.

17. M.L.Chen, J. S. Bae and W. C. Oh, Carbon Sci., 7, 259(2006).

18. M. L.Chen, J. S. Bae and W. C.Oh, Bull. Korean Chem. Soc., 27, 1423(2006).

19. M. L.Chen, J. S. Bae and W. C. Oh, Anal. Sci. Technol., 19, 376( 2006).

20. M. L. Chen, Y. S. Ko and W. C. Oh, Carbon Sci., 8(1), 6(2007).

21. M. Inagaki, Y. Hirose, T. Matsunaga, T. Tsumura and M. Toyoda, Carbon., 41, 2619(2003).

22. S. Karvinen, Solid State Sci., 5, 811 (2003).

23. K. Okada, N. Yamamoto, Y. Kameshima, A. Yasumori and K. Mackenzie, J. Am. Ceram. Soc., 84(7), 1591(2001).

24. S. D.Sharma, K.K. Saini, C. Kant, C.P. Sharma and S.C. Jain, Appl. Catal. B: Environ., 4, 17(2008).

25. Y. M. Kim, J. H. Lee, H. R. Jeong, Y. J. Lee, M. H. Um, K. M. Jeong, M. K. Yeo and M. S. Kang. J. Indust. Eng. Chem., 14, 396 (2008).

26. D. K. Zhang, Y. C. Liu, Y. L. Liu and H.Yang, Physi. B, 351, 178(2004).

27. S. F. Chen, W. Zhao, W. Liu and S. J. Zhang, Appl. Surf. Sci., 7, 115(2008).

28. P. F. Fu, Y. Luan and X.G. Dai, J. Mol. Catal. A: Chem., 221, 81 (2004). 